\title{
An experimental study of acute subarachnoid haemorrhage in baboons: changes in cerebral blood volume, blood flow, electrical activity and water content
}

\author{
H KUYAMA, A LADDS, NM BRANSTON, M NITTA, L SYMON \\ From the Gough Cooper Department of Neurological Surgery, Institute of Neurology, the National Hospital \\ for Nervous Diseases, Queen Square, London, UK
}

SUMMARY Subarachnoid haemorrhage following transection of the posterior communicating artery was produced in 10 baboons. Cerebral blood volume (CBV) decreased transiently after subarachnoid haemorrhage. Two basic patterns of intracranial pressure (ICP) were observed; in one ICP returned to normal but in the other it remained elevated. In this latter group four out of five animals showed an increase in CBV above the original level. There were delays in sensory conduction (measured using somatosensory evoked potentials) bilaterally; those on the contralateral side to the bleed were correlated with ICP whereas other factors are implicated on the ipsilateral side. Initial flow reduction and restoration of cerebral blood flow were both correlated with water content.

Subarachnoid haemorrhage following rupture of an intracranial aneurysm may produce severe focal neurological disturbance. A major cause of such disturbance has been considered to be changes in cerebral perfusion, which may be due to vasospasm ${ }^{12}$ and a concomitant rise in intracranial pressure (ICP). ${ }^{3}$ Other factors such as cerebral oedema, ${ }^{4}$ mechanical distortion of intracranial structures ${ }^{5}$ and intracerebral haematoma might also be responsible for neurological dysfunction. Cerebral haemodynamics after subarachnoid haemorrhage have been studied mainly by measuring cerebral blood flow (CBF). Cerebral blood volume (CBV) has also been regarded as an important factor not only in regulation of the cerebral circulation but also from its effect on ICP in pathological conditions. ${ }^{6}$ The behaviour of CBV following subarachnoid haemorrhage, however, is poorly understood.

Somatosensory evoked potentials (SEP) have been used clinically to monitor patients with subarachnoid haemorrhage. The timing of the centrally

Address for reprint requests: Professor L Symon, National Hospital for Nervous Diseases, Queen Square, London WC1N 3BG, UK.

Received 12 July 1983 and in revised form 23 October 1983 Accepted 8 November 1983 conducted afferent volley passing from the neck to the cerebral cortex (central conduction time (CCT)) has been suggested as a useful monitor of developing ischaemia.?

In this study, we have measured ICP, CBF, CBV, water content and SEP to study the changes in cerebral haemodynamics and cerebral function in the acute stage of experimental subarachnoid haemorrhage.

\section{Method}

\section{Anaesthesia and surgical techniques}

Ten baboons (Papio cynocephalus) in the weight range 7-11 kg were sedated with ketamine hydrochloride injected intramuscularly, intubated under light sodium thiopentone anaesthesia, and maintained normocapnic using pure oxygen delivered by a Starling pump. Anaesthesia was maintained with alpha-chloralose, $60 \mathrm{mg} / \mathrm{kg}$ given intravenously. The animals were immobilised with gallamine triethiodide ( $1 \mathrm{mg} / \mathrm{kg}$ iv) prior to surgery. Endtidal $\mathrm{CO}_{2}$, mean systemic arterial pressure, $\mathrm{PaO}_{2}, \mathrm{PaCO}_{2}$, $\mathrm{pH}$ and body temperature were monitored.

A 5-0 silk thread was passed around the left posterior communicating artery (PComA) transorbitally. The tails of silk were threaded through a polyethylene catheter (internal diameter: $0.76 \mathrm{~mm}$ ) whose tip was close to the PComA. Small muscle fragments were secured with cyanoacrylate glue to close the dural defect and the orbit 
was sealed with silicone rubber. Following removal of the scalp and temporal muscles bilaterally, the animal's head was fixed in a stereotactic apparatus (Narashige Model SN3). Eight burr holes were made symmetrically. Two of them were used for epidural pressure transducers ${ }^{8}$ in the parasagittal frontal regions. The other six burr holes for CBF measurements consisted of: Area A-the Sylvian operculum, Area B - the cortical sensory area identified by localising the SEP from stimulation of the contralateral median nerve, and Area C-the frontal parasagittal region. ${ }^{9}$ Deep electrodes for CBF were introduced stereotaxically through the burr holes in Area $\mathrm{C}$ into the thalamus (VPL) using the atlas of Davis and Huffman. ${ }^{10}$ An additional burr hole was made in each parietal region for CBV measurements. The burr holes were closed with acrylic resin to prevent subsequent leakage of cerebrospinal fluid.

\section{Regional CBF measurements}

Cortical and thalamic blood flow was measured by the hydrogen clearance technique using epoxy insulated platinum wire electrodes with a bared tip of $1 \mathrm{~mm}$ in length and $125 \mu$ in diameter. Two electrodes were implanted in each region, giving a total of 16 electrodes. A reference electrode of silver/silver chloride was placed in the oral cavity and this also acted as the common-mode for the SEP system. CBF values were calculated using the initial slope technique."

\section{Regional $C B V$ measurements}

CBV was measured by a photoelectric method. Two CBV sensors were applied on each parietal brain surface through burr holes (fig 1). The CBV sensor was designed to measure the brain tissue optical absorption indicating the changes of CBV. ${ }^{12}$ The apparatus consists of a $1 \mathrm{~mm}$ tungsten lamp (Hamai Electric Co, Tokyo, H-0116) and a photodiode $\left(10 \mathrm{~mm}^{2}\right.$ in sensitive area and $1 \mathrm{~mm}$ in thickness, Sharp Electric Co, Tokyo, SBC 255) covered with a filter (Kodak Co, Wratten gelatin filter No 55) (fig 1). This filter was used to avoid the influence of changes in blood gases. Silicone rubber was used to maintain the photodiode at $10 \mathrm{~mm}$ distance from the lamp. The size of the sensor was thus $7 \mathrm{~mm}$ in width, $15 \mathrm{~mm}$ in length and $2 \mathrm{~mm}$ in thickness. The outputs of the photodiode were connected to a polygraph (Beckman) which continuously recorded the changes in CBV together with epidural pressure and systemic arterial blood pressure. Calibration of CBV sensors was carried out by adjusting their gains to the same sensitivity during $5 \% \mathrm{CO}_{2}$ inhalation.

\section{Somatosensory evoked potential recording}

SEP was recorded in nine baboons. Silver cup electrodes were placed over the median nerve and the voltage of the stimulus pulse $(1.2 \mathrm{~Hz}$ prf) was adjusted to produce a thumb twitch, prior to immobilisation with gallamine triethiodide. A partial laminectomy was performed at C2 and a silver ball electrode placed over the midline on the dura. A silver/silver chloride reference electrode was placed on the dura in the frontal midline (Fpz), and silver electrodes were placed bilaterally over the focus of the SEP on the postcentral gyrus (Area B). The SEP waveforms were amplified and averaged using a PDP-11 based system as described elsewhere. ${ }^{13}$ Contralateral

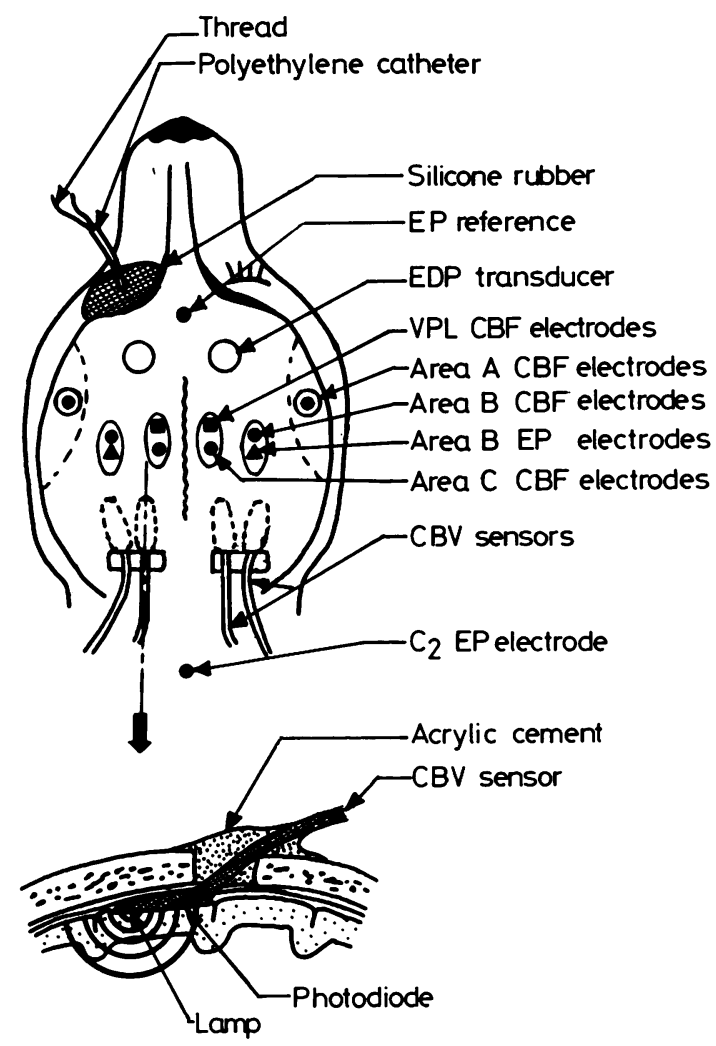

Fig 1 Schematic drawing of the experimental model. Upper: plane diagram of animal head. Lower: cross-sectional view at the dotted line with the arrow as shown in the upper diagram.

responses were recorded for the first $20 \mathrm{~ms}$ in averaged runs of 512 sweeps during the control phase of each experiment and in sequential runs of 64 sweeps immediately following the subarachnoid haemorrhage event.

The latency of the first positive peak P5 of the neck response was subtracted from that of the first cortical negative peak N10 to give a measure of central conduction, denoted by CT in this as in previous work. ${ }^{13}$ This measure was judged more reliable than CCT as used clinically, for which the first negative peak in the neck response is used instead of P5; the difference between CT and CCT is numerically constant, so that any changes in each will be identical.

\section{Water measurements}

At least five samples of grey and white matter were taken from Area A, Area B, Area C and caudate nucleus. The samples ( $1 \mathrm{~mm}$ cube) were immediately dropped into precalibrated columns of a kerosene/bromobenzene mixture prepared with graded density ${ }^{14}$ and their specific gravity was measured. The average water content, in units of $\mathrm{mg} / \mathrm{g}$ of tissue, was calculated for each region using an assumed constant value for the specific gravity of tissue solids. 


\section{Experimental procedures}

After the determination of two basal blood flows at $\mathrm{PaCO}_{2}$, $35-40 \mathrm{mmHg}, \mathrm{PaCO}_{2}$ was raised to $50-55 \mathrm{mmHg}$ by adding $5 \% \mathrm{CO}_{2}$ to the inlet of the ventilator in order to estimate $\mathrm{CO}_{2}$ reactivity and to adjust the gain of each CBV sensor. $\mathrm{CO}_{2}$ reactivity was evaluated as the percentage change in $\mathrm{CBF}$ per torr change in $\mathrm{PaCO}_{2}$. $\mathrm{CBF}$ was measured again at normocapnia and then subarachnoid haemorrhage was produced by pulling the snare around the PComA, desaturation of hydrogen being started simultaneously. CBF was measured at $1,15,30,60$ minutes after subarachnoid haemorrhage and $\mathrm{CO}_{2}$ reactivity was then checked. CBV was monitored for the duration of the experiment. Autoregulation was tested to a rise in blood pressure by metaraminol tartrate (Aramine) infusion at a rate of $0 \cdot 1-0.5 \mathrm{mg}$ per minute. Two hours after subarachnoid haemorrhage the animal was killed by $\mathrm{KCl}$ intravenously and the brain was quickly removed and placed in kerosene prior to water measurements.

\section{Results}

CHANGES IN ICP, CPP, CBV AND CBF

All ten baboons showed an abrupt elevation of ICP to $114 \pm 37 \mathrm{mmHg}$ immediately after subarachnoid haemorrhage and followed by two patterns of ICP. We divided the animals into two groups on the basis of these ICP patterns. ${ }^{15}$ In Group 1, ICP returned to normal range or to a level slightly higher than the control level. In Group 2, ICP remained elevated. Both groups contained five animals.

Figure 2 shows a typical pattern of change in ICP and $C B V$ recorded after subarachnoid haemorrhage

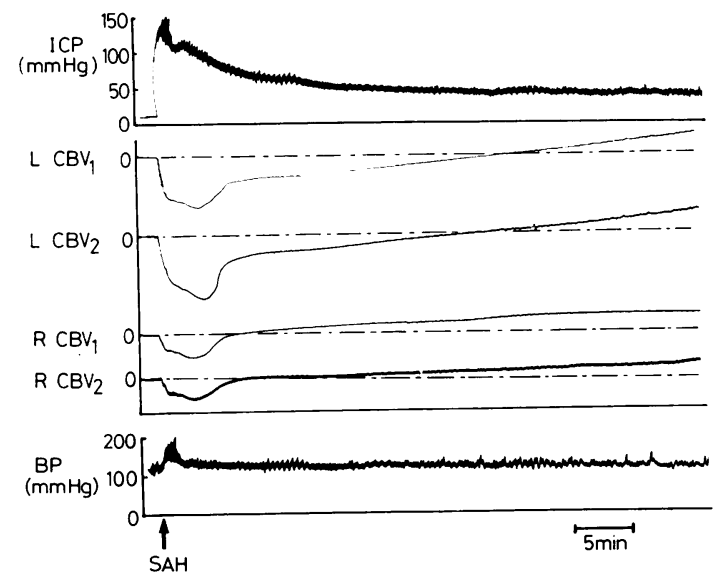

Fig 2 Polygraphic recording following subarachnoid haemorrhage which caused marked and rapid rise in ICP which was accompanied by relatively gradual reduction of $C B V$. Left $C B V$ was more affected than right $C B V$. $C B V$ gradually increased 4 minutes after subarachnoid haemorrhage on the left side and 3 minutes on the right side (SAH 4).
(Group 2, subarachnoid haemorrhage 4). Subarachnoid haemorrhage caused a relatively gradual decrease of CBV, which was followed by a gradual restoration and then continuous increase above the original level.

Figures 3 and 4 illustrate the changes in ICP, CPP, $\mathrm{CBV}$ and $\mathrm{CBF}$ in each group. $\mathrm{CBV}$ was measured in nine animals. The left side was the origin of the haemorrhage. In Group 1 (fig 3) ICP rose to $88 \pm$ $36 \mathrm{mmHg}$ and mean $\mathrm{CBF}$ values averaged over Areas A, B and C fell to $39 \cdot 6 \pm 16 \cdot 1 \%$ of control in the left hemisphere and $62 \cdot 1 \pm 21 \cdot 3 \%$ in the right immediately after subarachnoid haemorrhage. CBF recovered to $87.0 \pm 14.7 \%$ of control on the left side and $87 \cdot 1 \pm 19.2 \%$ on the right 15 minutes after subarachnoid haemorrhage, when ICP was $17 \pm 9$ $\mathrm{mmHg}$. CBV on the left side showed a greater decrease than on the right and the reduction was more prolonged. CBV returned to control levels on both sides within 20 minutes after subarachnoid haemorrhage. In two animals (subarachnoid haemorrhage 2,8 ) the time for left CBV to reach the minimum was about 4 minutes after subarachnoid haemorrhage, which was later than either that of right CBV or that of lowest CPP.

In Group 2 (fig 4) the maximum ICP elevation was $139 \pm 15 \mathrm{mmHg}$ at which time $\mathrm{CBF}$ on the left side was $29.4 \pm 14 \cdot 1 \%$ of control and on the right $38.8 \pm 14.9 \%$. Fifteen minutes after subarachnoid haemorrhage, ICP was $63 \pm 40 \mathrm{mmHg}$ and flows in the left and right hemisphere were $62 \cdot 1 \pm 37 \cdot 1 \%$ of control and $77 \cdot 1 \pm 31.8 \%$ respectively. CBV on the left side was more affected than the right. In three animals (subarachnoid haemorrhage $3,4,5$ ) CBV increased above the original level on both sides and one animal showed increased CBV on the right side (left was not available) while another one showed rapid return of CBV to the control level. Four animals (subarachnoid haemorrhage $4,5,9,10$ ) showed that the time for left CBV to reach the minimum was 3 to 5 minutes after subarachnoid haemorrhage, which was later than either that of right CBV or that of lowest CPP.

Two animals (subarachnoid haemorrhage 5,9) showed rebleeding, recognised by sudden elevation of ICP and one of them had two such episodes.

\section{CHANGES IN CBF IN EACH REGION}

Control values of $\mathrm{CBF}$ in the various regions are shown in table 1 . There was no significant difference in the corresponding areas between the two sides. Figure 5 shows the changes in CBF in each region following subarachnoid haemorrhage. Subarachnoid haemorrhage caused significantly decreased CBF which returned to normal 15 minutes after subarachnoid haemorrhage in all areas. In Area $A$ and 

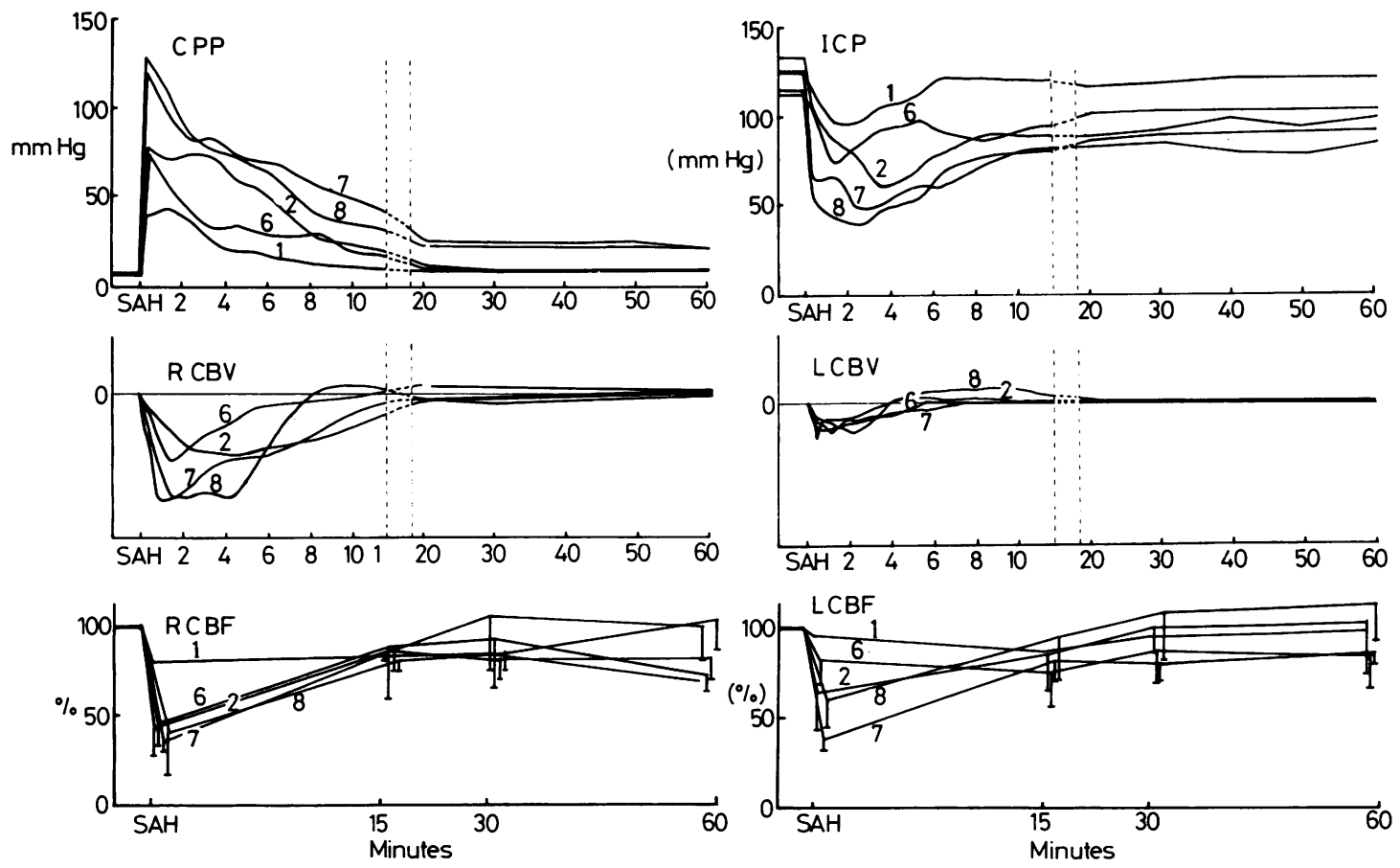

Fig 3a and b Tracings of ICP, CPP, CBV and CBF after subarachnoid haemorrhage in Group 1 (5 baboons). The number against individual trace indicates the individual animal used for the experiment. Values of $C B F$ were averaged over Areas $A, B$ and $C$. All values are mean \pm standard deviation.
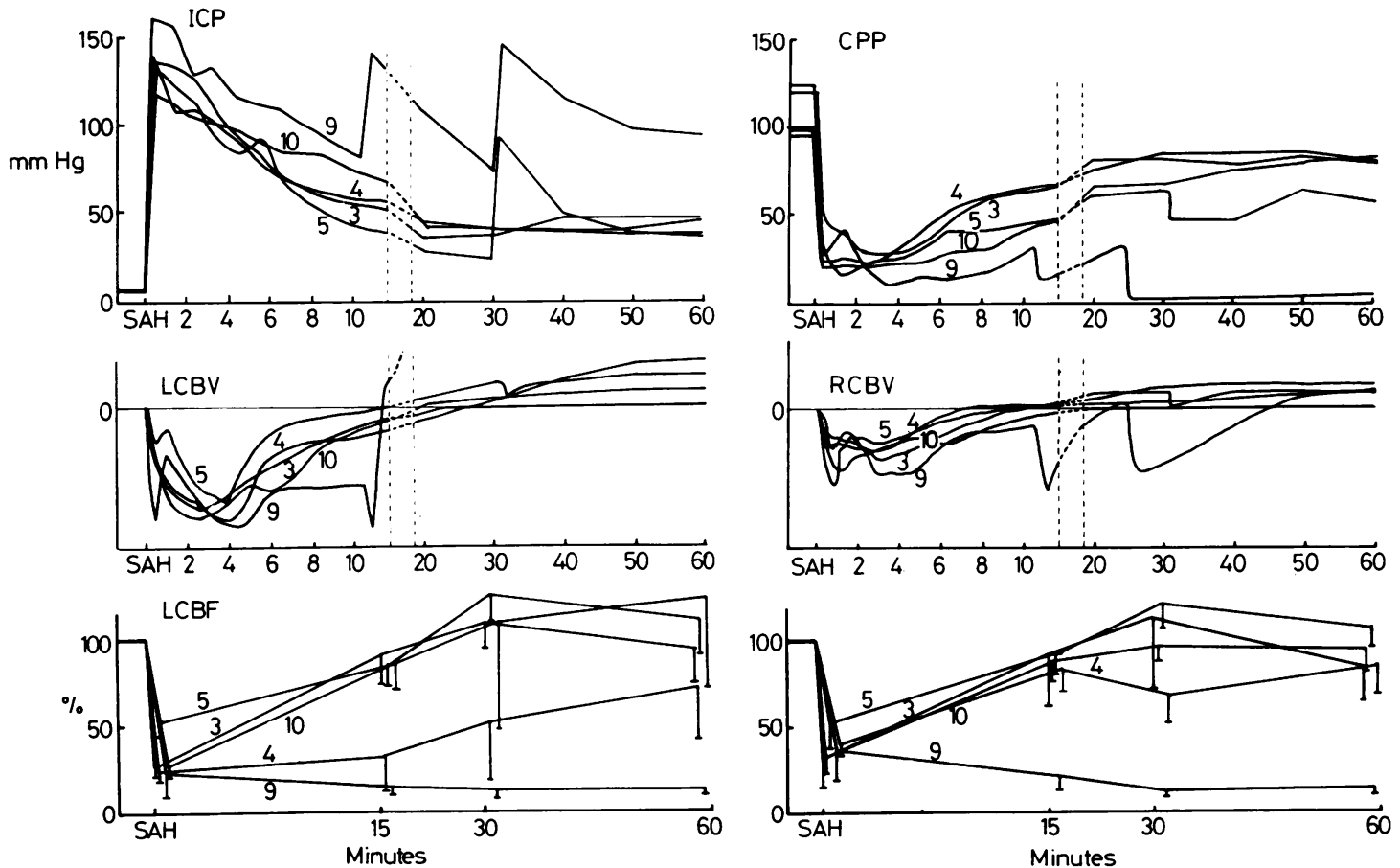

Fig 4a and b Tracings of ICP, CPP, CBV and CBF after subarachnoid haemorrhage in Group 2 (5 baboons). The humps of ICP seemed to be due to rebleedings. As in fig 3, the number against individual trace indicates the individual animal. Values of $C B F$ were averaged over Areas $A, B$ and $C$. All values are mean \pm standard deviation. 
Table 1 Control values of CBF in the various regions $(\mathrm{ml} / 100 \mathrm{~g} / \mathrm{min})$

\begin{tabular}{|c|c|c|c|c|c|c|c|c|}
\hline & \multicolumn{2}{|c|}{ Area $A$} & \multicolumn{2}{|c|}{ Area $B$} & \multicolumn{2}{|c|}{ Area $C$} & \multicolumn{2}{|l|}{$V P L$} \\
\hline & Left & Right & Left & Right & Left & Right & Left & Right \\
\hline $\begin{array}{l}\text { Mean } \\
\text { SD }\end{array}$ & $\begin{array}{r}38.4 \\
8.6\end{array}$ & $\begin{array}{r}44 \cdot 1 \\
9 \cdot 4\end{array}$ & $\begin{array}{r}39.6 \\
6.4\end{array}$ & $\begin{array}{r}45 \cdot 1 \\
8 \cdot 2\end{array}$ & $\begin{array}{l}52 \cdot 6 \\
14.4\end{array}$ & $\begin{array}{l}48 \cdot 0 \\
11 \cdot 2\end{array}$ & $\begin{array}{l}63 \cdot 8 \\
20 \cdot 8\end{array}$ & $\begin{array}{l}55 \cdot 2 \\
21 \cdot 9\end{array}$ \\
\hline
\end{tabular}

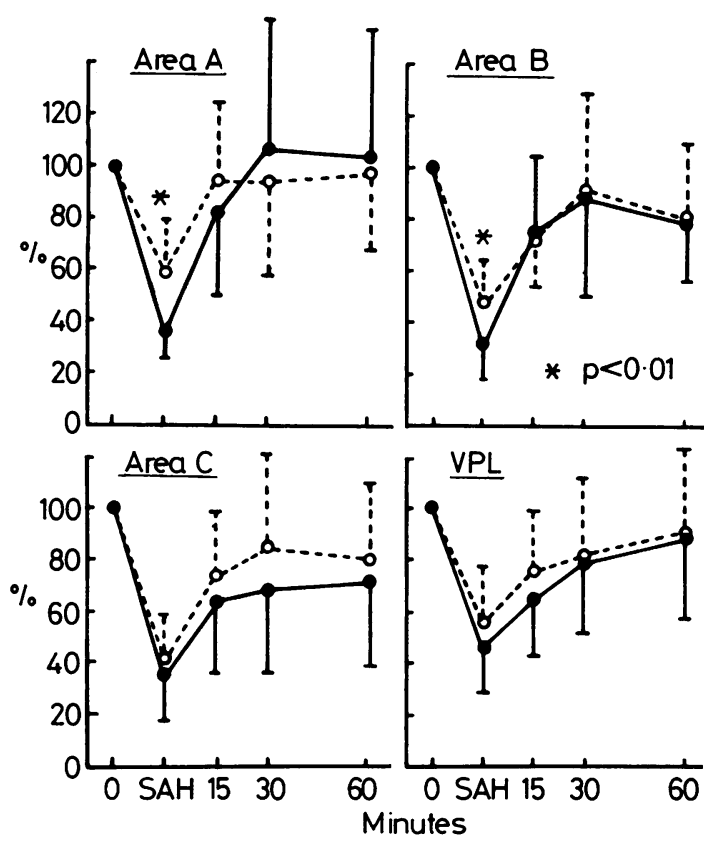

Fig 5 Changes in CBF of each area after subarachnoid haemorrhage in ten baboons. Solid lines show the left side and dotted lines the right side. All values are mean \pm standard deviation.
$B, C B F$ on the left side was slightly but significantly lower (Area A: p $<0.01$, Area B: $p<0.01$ ) than on the right side immediately after subarachnoid haemorrhage. However, there were no significant differences between the sides 15 minutes after subarachnoid haemorrhage. In Area $C$ and VPL, the changes in CBF were not significantly different between the sides following subarachnoid haemorrhage.

\section{CHANGES IN SEP}

The average value of CT was $5.4 \pm 0.4$ ms (mean \pm SD). Values of CT and flow in the SEP cortical recording area (Area B) during the control phase were not significantly different from those found in previous work ${ }^{13}$ involving a model which used middle cerebral artery occlusion to produce the basic ischaemic lesion.

Figure 6 shows the changes in CT from control values measured on the left and right sides during the 60 minutes following subarachnoid haemorrhage. On the left side, the cortical response was abolished in three animals and failed to return in two of these. There were also marked increases in CT of up to $3.0 \mathrm{~ms}$. Table 2 shows that during the first five minutes after subarachnoid haemorrhage, CT was not significantly different from control on the left side, but it was significantly lengthened on the right side $(p<0.025)$. By 10 minutes it was

Table 2 Changes in CT from control (ms) in left and right Area $B$ when flow immediately after subarachnoid haemorrhage was less than $22 \mathrm{ml} / 100 \mathrm{~g} / \mathrm{min}$

\begin{tabular}{|c|c|c|c|c|c|c|c|c|}
\hline \multirow{2}{*}{$\begin{array}{l}\text { Time after } \\
\text { SAH } \\
\text { Site } \\
\text { Exp No }\end{array}$} & \multicolumn{2}{|c|}{$0-5 \mathrm{~min}$} & \multicolumn{2}{|c|}{$5-10 \mathrm{~min}$} & \multicolumn{2}{|c|}{$10-15 \mathrm{~min}$} & \multicolumn{2}{|c|}{$15-20 \mathrm{~min}$} \\
\hline & Left & Right & Left & Right & Left & Right & Left & Right \\
\hline $\begin{array}{lr}\text { SAH } & 2 \\
\text { SAH } & 3 \\
\text { SAH } & 4 \\
\text { SAH } & 5 \\
\text { SAH } & 6 \\
\text { SAH } & 7 \\
\text { SAH } & 8 \\
\text { SAH } & 9 \\
\text { SAH } & 10\end{array}$ & $\begin{array}{l}\text { na } \\
-0.1 \\
-0.1 \\
+0.2 \\
+0.1 \\
+0.6 \\
+0.1 \\
+0.8 \\
+0.1\end{array}$ & $\begin{array}{l}\text { na } \\
\text { na } \\
+0.3 \\
+0.4 \\
\text { f } \\
+0.3 \\
+0.1 \\
+0.6 \\
+0.1\end{array}$ & $\begin{array}{l}+2.1 \\
+0.8 \\
\text { abs } \\
+0.9 \\
+0.1 \\
+1 \cdot 1 \\
+0.1 \\
+1 \cdot 1 \\
+0.1\end{array}$ & $\begin{array}{l}-0.1 \\
+1.1 \\
+0.2 \\
+0.8 \\
\mathrm{f} \\
-0.1 \\
-0.1 \\
+1.4 \\
+0.1\end{array}$ & $\begin{array}{l}+3.0 \\
+0.7 \\
\text { abs } \\
+0.9 \\
+0.4 \\
+1.3 \\
\text { na } \\
+1.9 \\
0\end{array}$ & $\begin{array}{l}\quad 0 \\
+0.4 \\
+0.2 \\
+0.7 \\
\text { f } \\
\text { na } \\
+0.3 \\
+1.4 \\
\text { na }\end{array}$ & $\begin{array}{l}+2.1 \\
+0.6 \\
\text { abs } \\
+0.9 \\
+0.4 \\
+0.5 \\
+0.3 \\
\text { abs } \\
+0.1\end{array}$ & $\begin{array}{c}-0.1 \\
+0.3 \\
0 \\
+0.6 \\
\mathrm{f} \\
+0.1 \\
+0.2 \\
\text { abs } \\
+0.2\end{array}$ \\
\hline $\begin{array}{l}\text { Mean } \\
\text { SD } \\
p^{*}\end{array}$ & 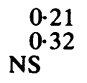 & $\begin{array}{l}0.30 \\
0.18 \\
0.025\end{array}$ & $\begin{array}{l}0.79 \\
0.69 \\
0.025\end{array}$ & $\begin{array}{l}0.48 \\
0.57 \\
0.05\end{array}$ & $\begin{array}{l}1 \cdot 17 \\
1.01 \\
1 \cdot 025\end{array}$ & $\begin{array}{l}0.50 \\
0.50 \\
\text { NS }\end{array}$ & $\begin{array}{l}0.70 \\
0.67 \\
0.05\end{array}$ & $\begin{array}{l}0.19 \\
0.23 \\
\text { NS }\end{array}$ \\
\hline
\end{tabular}

${ }^{*} \mathrm{p}$ for paired $t$ test deviation from zero.

na: not available, abs: cortical response abolished, f: flow more than $22 \mathrm{ml} / 100 \mathrm{~g} / \mathrm{min}, \mathrm{SAH}$ : subarachnoid haemorrhage. 
(a)
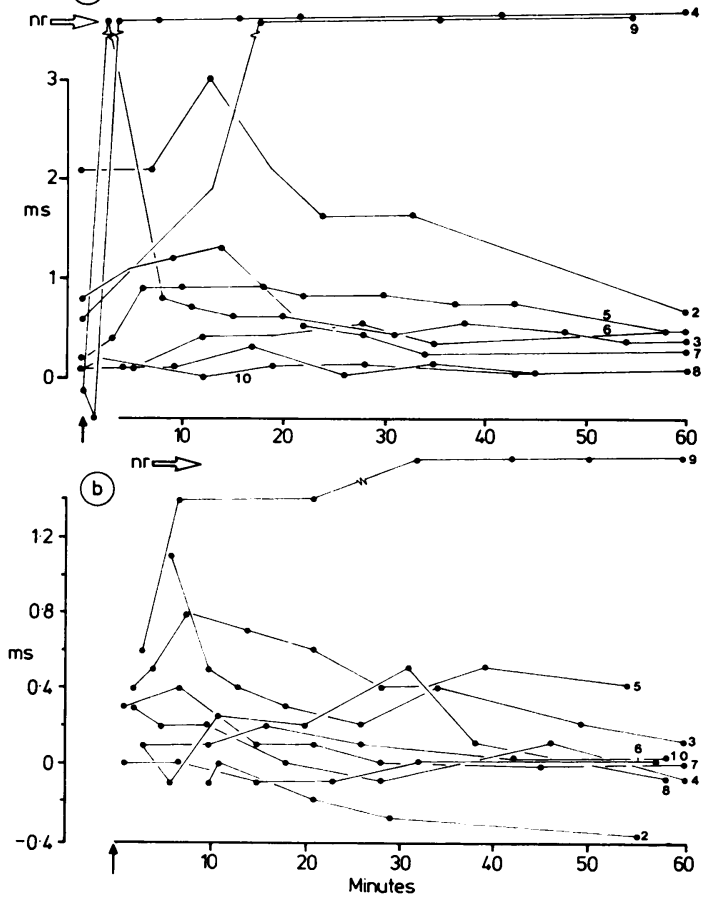

Fig 6 Changes in CT from control during the 60 minutes following subarachnoid haemorrhage (indicated by the arrow). (a) Left side, (b) Right side. As in fig 3, small numbers indicate individual animals. The letters $\mathrm{nr}$ indicate loss of the cortical response.

significantly increased bilaterally and by 15 minutes, CT on the right side was not significantly different from control, although it remained so on the left side until 20 minutes after the subarachnoid haemorrhage. After one hour, CT had begun to return towards normal on the left side in all but two animals. Overall, CT increases were larger on the left side following subarachnoid haemorrhage, and table 2 shows the changes from control values in time bands at cortical sites where the flow immediately after subarachnoid haemorrhage was less than 22 $\mathrm{ml} / 100 \mathrm{~g} / \mathrm{min}$. This figure was chosen arbitrarily because most of the post-subarachnoid haemorrhage cortical flows were below it.

There was a significant positive correlation between the highest initial ICP following subarachnoid haemorrhage and maximum increase in CT on the right side $(r=0.84, p<0.01)$. The left side, however, showed no such correlation.

\section{THE RELATIONSHIP BETWEEN WATER CONTENT} AND CHANGES IN CBF

Figure 7 shows the water content of each region of all animals. Control values were taken from previ-

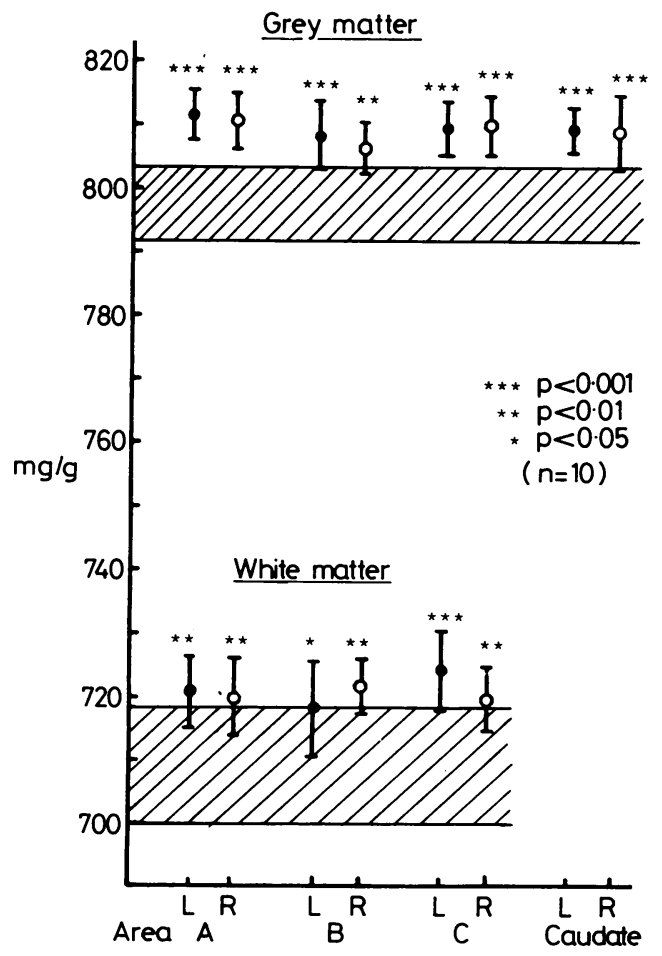

Fig 7 Water content 2 hours after subarachnoid haemorrhage. Upper shaded zone: control value of grey matter. Lower shaded zone: control value of white matter. All values are mean \pm standard deviation.

ous experiments in animals similarly anaesthetised. ${ }^{16}$ All regions showed a significant increase of water content and there was a more general elevation of water content in grey matter than in white matter. No significant difference in water content was shown between corresponding regions in the two hemispheres.

This result corresponded with the tracings of CBV which decreased during $\mathrm{CO}_{2}$ inhalation (fig 10). The generally depressed level of $\mathrm{CO}_{2}$ reactivity in this trace has resulted in apparent steal beneath the areas of the photoelectric cells, resulting in a reduction of local cerebral blood volume. The reduced compliance of the entire system secondary to subarachnoid haemorrhage and swelling is reflected in the considerable rise in ICP, presumably from areas of brain retaining more $\mathrm{CO}_{2}$ reactivity where blood volume would doubtless increase.

Figure 8 illustrates the significant correlation between the increase in water content and the reduction of $\mathrm{CBF}$ immediately after subarachnoid haemorrhage $(p<0 \cdot 01)$.

Figure 9 shows a significant relationship $(p<0.001)$ between the increase of water and the 


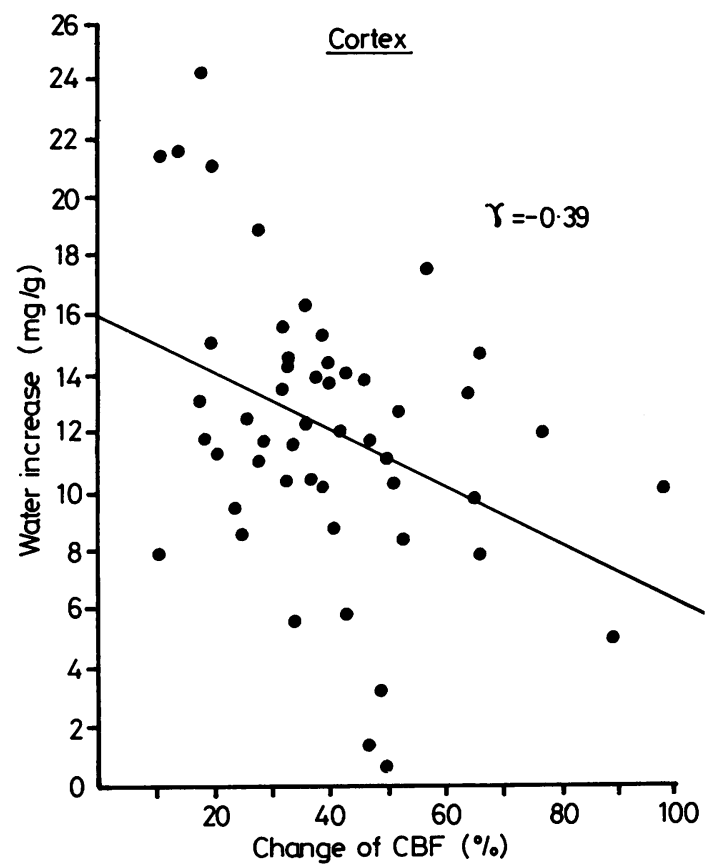

Fig 8 Plot of water increase versus initial flow reduction.

restoration of CBF following subarachnoid haemorrhage, calculated as the difference in percentage change in CBF immediately after and 15 minutes after subarachnoid haemorrhage. In this analysis we excluded the results from subarachnoid haemorrhage 9, where there was no restoration of $\mathrm{CBF}$ (fig 4).

$\mathrm{CO}_{2}$ REACTIVITY AND AUTOREGULATION

$\mathrm{CO}_{2}$ reactivity was estimated by calculating the mean percentage changes in $\mathrm{CBF}$ averaged over Areas $\mathrm{A}, \mathrm{B}$ and $\mathrm{C}$ per $\mathrm{mmHg}$ change in $\mathrm{PaCO}_{2}$. The value of $\mathrm{CO}_{2}$ reactivity before subarachnoid haemorrhage was not significantly different between the two groups. However, $\mathrm{CO}_{2}$ reactivity after subarachnoid haemorrhage was impaired in both groups and the value of $\mathrm{CO}_{2}$ reactivity in Group 2 was significantly lower than Group 1 (left side:

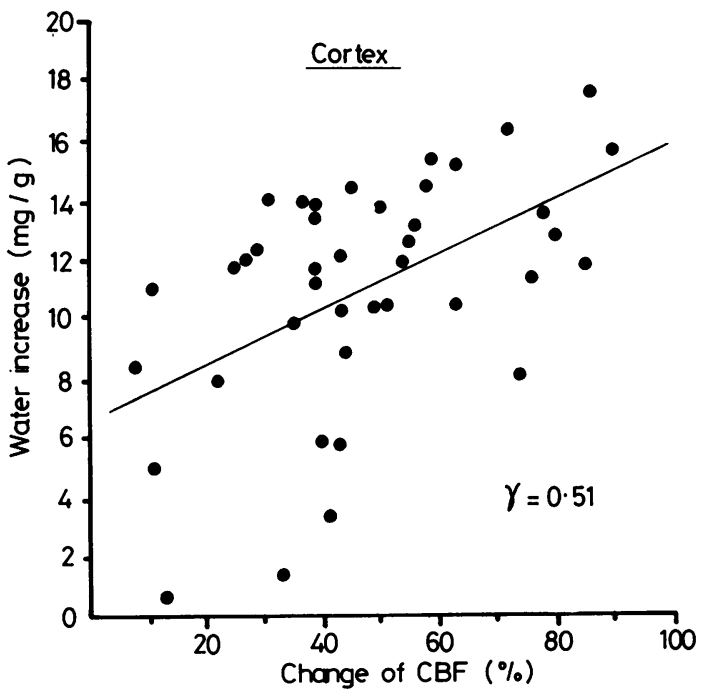

Fig 9 Plot of water increase versus restoration of CBF following subarachnoid haemorrhage.
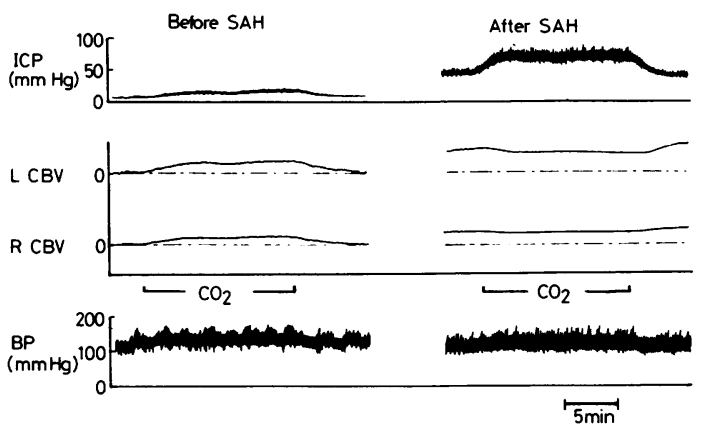

Fig $10 \mathrm{CO}_{2}$ reactivity before and after subarachnoid haemorrhage (SAH 4).

$\mathrm{p}<0.01$, right side: $\mathrm{p}<0.01$ ) (table 3 ). In Group $2, \mathrm{CO}_{2}$ reactivity in the left side was negative. This result corresponded with the tracings of $\mathrm{CBV}$ which decreased during $\mathrm{CO}_{2}$ inhalation (fig 10).

The percentage of ICP change per $\mathrm{mmHg} \mathrm{PaCO}_{2}$ was also calculated in each group. Subarachnoid

Table $3 \mathrm{CO}_{2}$ reactivity (\% change of $\mathrm{CBF} / \mathrm{PaCO}_{2}$ change)

\begin{tabular}{|c|c|c|c|c|}
\hline & \multicolumn{2}{|l|}{ Left } & \multicolumn{2}{|l|}{ Right } \\
\hline & Before $S A H$ & After $S A H$ & Before $S A H$ & After $S A H$ \\
\hline Group 1 & $\begin{array}{l}3 \cdot 88 \pm 2 \cdot 36 \\
(n=12)\end{array}$ & $\begin{array}{l}1 \cdot 85 \pm 1 \cdot 01 \\
(\mathrm{n}=12)\end{array}$ & $\begin{array}{l}4 \cdot 23 \pm 2 \cdot 08 \\
(n=10)\end{array}$ & $\begin{array}{l}2 \cdot 72 \pm 1 \cdot 51 \\
(n=10)\end{array}$ \\
\hline Group 2 & $\begin{array}{l}3 \cdot 09 \pm 1 \cdot 81 \\
(n=15)\end{array}$ & $\begin{array}{l}-0.28 \pm 1.77 \\
(\mathrm{n}=15)\end{array}$ & $\begin{array}{l}4 \cdot 34 \pm 1 \cdot 85 \\
(n=14)\end{array}$ & $\begin{array}{l}0 \cdot 24=1 \cdot 77 \\
(n=15)\end{array}$ \\
\hline
\end{tabular}

$\left({ }^{*} \mathrm{p}<0.01\right)$ 
Table 4 ICP changes during $\mathrm{CO}_{2}$ inhalation (\% change of $\mathrm{ICP} / \mathrm{PaCO}{ }_{2}$ change)

\begin{tabular}{lll}
\hline & Before SAH & After SAH \\
\hline Group 1 & $\begin{array}{l}16 \cdot 0 \pm 6 \cdot 4 \\
(\mathrm{n}=5)\end{array}$ & $\begin{array}{l}11 \cdot 3 \pm 2 \cdot 6 \\
(\mathrm{n}=5)\end{array}$ \\
Group 2 & $\begin{array}{l}15 \cdot 7 \pm 4 \cdot 5 \\
(\mathrm{n}=5)\end{array}$ & $\begin{array}{l}4 \cdot 2 \pm 2 \cdot 3 \\
(\mathrm{n}=5)\end{array}$ \\
\hline
\end{tabular}

$\left({ }^{*} \mathrm{p} 0 \cdot 01\right)$

Table 5 Autoregulation after $S A H$ (\% change of $C B F / B P$ change)

\begin{tabular}{lll}
\hline & Left & Right \\
\hline Group 1 & $\begin{array}{l}0.51 \pm 0.53 \\
(\mathrm{n}=11)\end{array}$ & $\begin{array}{l}0.24 \pm 0.24 \\
(\mathrm{n}=10)\end{array}$ \\
Group 2 & $\begin{array}{l}1.04 \pm 1.09 \\
(\mathrm{n}=11)\end{array}$ & $\begin{array}{l}0.95 \pm 0.70 \\
(\mathrm{n}=13)\end{array}$ \\
\hline
\end{tabular}

$\left({ }^{*} \mathrm{p} 0 \cdot 01\right)$

haemorrhage reduced this value from $16 \cdot 0 \pm 6 \cdot 4$ to $11.3 \pm 2.6$ in Group 1 and from $15.7 \pm 4.5$ to $4 \cdot 2 \pm$ 3.0 in Group 2 . There was a significant difference $(p<0.01)$ between the two groups after subarachnoid haemorrhage (table 4).

Autoregulation in Group 2 tended to be more disturbed than Group 1 (right side: significant $(p<0 \cdot 01)$, left side: not significant) (table 5).

\section{Discussion}

Two types of experimental models have been devised to induce subarachnoid haemorrhage. One is injection or topical application of blood in the CSF spaces ${ }^{2} 1718$ and the other is rupture or puncture of an intracranial artery. ${ }^{19} 2021$ The former method is not only unlike the clinical situation caused by the rupture of an intracranial aneurysm but also inadequate for assessment of the exact changes in CBV in the acute stage of subarachnoid haemorrhage. Any measurement must admit the possibility that $C B V$ will be affected by the extravasation of blood from the local circulation at the time of the haemorrhage.

One method to produce bleeding from an intracranial vessel is withdrawal of a needle previously inserted into an intracranial artery. However, this method can traumatise the artery and disturb blood flow in the vessel in the control stage. We have therefore preferred posterior communicating artery transection, which produces acute increase of ICP and neurological deficit in recovered animals. ${ }^{21}$

Only scattered reports are available concerning changes in CBV with subarachnoid haemorrhage, although $\mathrm{CBV}$ has been considered to play an important role in regulating cerebral haemodynamics. Such previous studies on CBV have been performed by using radioiodinated serum albumin ${ }^{22}$ or observation of cerebral vessels ${ }^{23}{ }^{24}$ in animals and by using radioactive oxygen-15 in humans. ${ }^{25}$

One of the advantages of the photoelectric method is that regional CBV is continuously measurable. Optical absorption in the brain tissue indicates changes in CBV. ${ }^{12}$ Both transmitted light and scattered light are measured to estimate the optical absorption in the illuminated brain and both change equally in accordance with changes in the volume of the vascular bed. ${ }^{12}$ We have measured the scattered light by the photoelectric device which was developed by Kuyama et al ${ }^{12}$ to avoid brain tissue injury (fig 1), since if transmitted light is to be measured in situ the light source must be implanted in the brain parenchyma. The method presents some problems. The first is that optical absorption depends not only on changes in CBV but also on the properties of red blood cells, such as aggregation and orientation. Klose et $a^{26}$ studied the relationship between the light transmission of human whole blood and the shear rate and demonstrated that below 60/s the light transmission increased with shear rate corresponding to deformation of red blood cells or to orientation. Thus, the value of CBV measured by the photoelectric method was presumably overestimated when CBV was markedly decreased as shown in the stage immediately after subarachnoid haemorrhage. On the other hand, when CBV was recovered, the value was possibly underestimated, since the photoelectric device mainly measures the blood volume in arterioles, capillaries and venules, where the shear rates of blood are higher than 80 / s. $^{27}$ However, these rheologically based errors are not great. According to Tomita $e$ al $^{28}$ the error of CBV estimated by the photoelectric methods was only $5 \%$ as the blood velocity was halved.

The second problem concerns calibration. Tomita et $a l^{28}$ calculated the absolute value of $\mathrm{CBV}$ in accordance with Lambert-Beer's law by measuring the optical density in the cerebral tissue before and after infusion of saline, which replaced the blood in the vascular bed at the end of the experiment. In the present experiment, CBV was not quantified to avoid any effect of replacement of saline on the cerebral oedema. $\mathrm{CBV}$ was calibrated during $\mathrm{CO}_{2}$ inhalation to adjust the gain of all CBV sensors to the same sensitivity. The third problem is artifact due to the spread of haematoma under the photoelectric device. To avoid this problem CBV sensors were applied on the surface of the posterior part of the brain. In one case (subarachnoid haemorrhage 9) which showed two recurrences of severe haemor- 
rhage, $\mathrm{CBV}$ on the side of the ruptured artery could not be measured after the second haemorrhage due to the spread of the extravasated blood (fig 4). However, in the other cases CBV was measurable during the entire course of experiments and no extravasated blood was seen under the device. Haematoma was usually localised in the basal cisterns, Sylvian fissures and interhemispheric fissure and, in some cases, over the lower convexity.

Our study showed that subarachnoid haemorrhage caused acute transient reduction in CBV following the haemorrhage, corresponding to the significant reduction in CBF observed after subarachnoid haemorrhage. The factors decreasing CBV may be a sudden rise in ICP, vasoconstriction and efflux of blood from the transected artery. In addition we observed difference in behaviour of CBV between the hemispheres within 15 minutes after subarachnoid haemorrhage in all animals. CBV was affected more intensely and for longer on the side of the ruptured artery. This initial CBV difference might result from differences in perfusion pressure, possibly due to the presence of arterial spasm, ICP gradient and efflux of blood from the ruptured artery. Our previous experiments with the same subarachnoid haemorrhage model showed that there was a pressure difference between the side of the ruptured vessel and the opposite side. This pressure difference was $11.2 \mathrm{mmHg}$ and lasted for $7 \cdot 3$ minutes. ${ }^{15}$ However, this degree of pressure difference alone is not likely to produce the observed difference in CBV. The efflux of blood is also unlikely to be responsible for the $\mathrm{CBV}$ difference, because the arrest of active haemorrhage occurs in the first few minutes when ICP is maximally elevated..$^{20}$

Symon $^{29}$ demonstrated that the average time for the spasm to reach its maximum was 3.8 minutes after traumatic stimulation of the middle cerebral artery in baboons. Other experimental models ${ }^{17} 18$ in which the diameter of the basilar artery in cats was measured showed that a marked vasoconstriction occurred 3 to 5 minutes after contact of blood with the vessels. In the present study, six out of nine animals showed that CBV on the side of the ruptured artery gradually decreased following subarachnoid haemorrhage and reached a minimum level 3 to 5 minutes after subarachnoid haemorrhage, which was later than either that of contralateral CBV or that of lowest CPP (figs 2, 3, 4). Four out of these six animals belong to Group 2 and the other two to Group 1 . These results suggest that the initial CBV difference is probably due to vasospasm which occurred more frequently in Group 2.

Four out of five animals in Group 2 showed that CBV gradually increased above the level of control. In Group $1 \mathrm{CBV}$ returned to the control level.
These results suggest that $\mathrm{CBV}$ increased in the condition of subarachnoid haemorrhage where haemorrhage was severe and ICP remained elevated. This may be supported by the results which showed that autoregulation in Group 2 tended to be more impaired than Group 1.

Grubb et $a l^{25}$ showed that there was a marked increase in CBV in patients with vasospasm and mild elevated CBV without vasospasm. They suggested that the increase in CBV with subarachnoid haemorrhage was the result of the dilatation of small intraparenchymal resistance vessels. On the other hand, Hart ${ }^{24}$ suggested that pooling of cerebral venous blood might be responsible for the increased CBV. Judging from the changes in CBF, our study showed that $\mathrm{CO}_{2}$ reactivity in the animals with increased CBV was significantly disturbed after subarachnoid haemorrhage compared with Group 1. This data was supported by results showing that ICP increase per $\mathrm{mmHg} \mathrm{PaCO}_{2}$ change in Group 2 was significantly lower than in Group 1 after subarachnoid haemorrhage. The increased CBV following subarachnoid haemorrhage may well result from dilatation of resistance vessels competing with increase in the arterial carbon dioxide tension in the production of relaxation and dilation of cerebral resistance vessels. ${ }^{30}$ Voldby's ${ }^{31}$ demonstration of elevated lactate in the CSF of patients with subarachnoid haemorrhage indicates that cerebral tissue lactacidosis may be another factor producing the dilatation of resistance vessels, since the small intraparenchymal resistance vessels are mainly under the influence of cellular metabolism. ${ }^{32}$

Our data showed that subarachnoid haemorrhage caused a significant reduction in CBF in all areas and suggested that the early vascular effects of subarachnoid haemorrhage are throughout the whole brain. There was a small but significant difference of CBF between the hemispheres in Areas A and B immediately after subarachnoid haemorrhage, corresponding with the change in $\mathrm{CBV}$ which was more decreased on the side of the ruptured artery.

The present study also showed that thalamic blood flow decreased markedly immediately after subarachnoid haemorrhage without significant difference from cortical flow. Martins et $^{a l^{3}}$ induced subarachnoid haemorrhage in the monkey by an injection of blood into the prechiasmatic subarachnoid space and showed the absence of any preferential reduction in flow to the deep nuclear areas after subarachnoid haemorrhage. Other workers ${ }^{2}$ who injected blood into the cisterna magna in cats and maintained ICP at normal value demonstrated that the reduction in CBF in the deep area was greater than in the cortex. These disparate results might be due to the different site of the injected blood rather 
than different ICP. It seems that the changes of haemodynamics are affected by the site of the haematoma which is one of the causes of vasospasm. ${ }^{33}$

It can be seen from fig 6 and table 1 that there were marked changes in CT following subarachnoid haemorrhage. It is interesting that these changes were bilateral although not as large on the right side as on the left side. They were comparable to those seen following middle cerebral artery occlusion in a similar preparation, although then they are confined to the side of the lesion. ${ }^{13}$ Flow relationships, however, were essentially the same on both sides in the present study. With this protocol the flows were not significantly different from control 15 minutes after subarachnoid haemorrhage which could help explain the return of CT toward control values by 60 minutes. ${ }^{34}$

The increase in CT appears related to the maximum level of ICP, a correlation not found for the left side. Perfusion pressure on the right side was temporarily decreased as a result of the increase in ICP and this is reflected in the flow changes. On the left side there are other factors, for instance, vasospasm resulting from the rupture of the artery and the extravasation of blood into the subarachnoid space, presumably influencing CT change more on the left side than on the right side.

The present study confirms the previous demonstration that cerebral oedema develops in the acute stage of experimental subarachnoid haemorrhage.

Shigeno et $\mathrm{al}^{35}$ suggested that gravimetric determination of cerebral water content can be influenced by the value of CBV. However, this influence seems to be small because changes in CBV did not correspond to the water content.

A recent study ${ }^{36}$ demonstrated the occurrence of blood-brain barrier breakdown after subarachnoid haemorrhage introduced by an arterial puncture, while other experiments ${ }^{37}$ showed preservation of the barrier following subarachnoid haemorrhage produced by intracisternal injection of whole blood. These differing results might be due to the different subarachnoid haemorrhage model and the varied time from the onset of subarachnoid haemorrhage to the injection of blood brain barrier indicators, although in both experiments the barrier was evaluated from the behaviour of Evans blue in the acute stage. The movement of water into the brain tissue and increased permeability of blood brain barrier to proteins are separate and independent phenomena because, increased water content has been observed without barrier breakdown. ${ }^{38}$

There was a weak but significant relationship between initial flow reduction and water increase. All areas in the animal with severe ischaemia (sub- arachnoid haemorrhage 9) showed the significant elevation $(p<0.001)$ of water content compared with the others. This result suggests that the severe prolonged ischaemia following subarachnoid haemorrhage is one of the factors producing cerebral oedema. It is also likely that CBF restoration in the early stage of acute subarachnoid haemorrhage may worsen the cerebral oedema. On the other hand $\mathrm{CBF}$ restoration occurring later may aid in resolution of the oedema, since previous experiments ${ }^{21}$ demonstrated that post-haemorrhagic hyperaemia observed immediately and two days after subarachnoid haemorrhage was a favourable prognostic sign. These relationships between changes in CBF and water content are, however, not enough to explain fully cerebral oedema following acute subarachnoid haemorrhage. Further investigation in experiments using chemical or metabolic parameters are clearly required.

We thank DJ Peters, C. Bashford and GS O' Neil for skilful technical assistance and Mrs Helen Craven for typing the manuscript.

\section{References}

' Allcock JM, Drake CG. Ruptured intracranial aneurysms-the role of arterial spasm. $J$ Neurosurg 1965;22:21-9.

${ }^{2}$ Umansky F, Kaspi T, Shalit MN. Regional cerebral blood flow in the acute stage of experimentally induced subarachnoid haemorrhage. J Neurosurg 1983;58:210-6.

${ }^{3}$ Martins AN, Doyle TF, Newby N, Kobrine Al, Ramirez A. The effect of a simulated subarachnoid haemorrhage on cerebral blood flow in the monkey. Stroke 1975;6:664-72.

${ }^{4}$ Marshall LF, Bruce DA, Graham DI, Langfitt TW. Alterations in behaviour, brain electrical activity, cerebral blood flow and intracranial pressure produced by triethyl tin sulphate induced cerebral oedema. Stroke 1976;7:21-5.

${ }^{5}$ McQueen JD, Jelsma LF. Intracranial hypertension. Cerebrospinal fluid pressure rises following intracisternal infusions of blood components in dogs. Arch Neurol 1967;16:501-8.

- Langfitt TW, Weinstein JD, Kassell NF. Cerebral vasomotor paralysis produced by intracranial hypertension. Neurology (Minneap) 1965;15:622-41.

' Symon L, Hargadine J, Zawirski M, Branston NM. Central conduction time as an index of ischaemia in subarachnoid haemorrhage. J Neurol Sci 1979;44:95103.

${ }^{8}$ Dorsch NWC, Stephens RJ, Symon L. An intracranial pressure transducer. Bio-Medical Engineering 1971;6:452-7.

9 Symon L, Pasztor E, Branston NM. The distribution and density of reduced cerebral blood flow following acute 
middle cerebral artery occlusion: An experimental study by the technique of hydrogen clearance in baboons. Stroke 1974;5:355-64.

${ }^{10}$ David R, Hoffman RD. A Stereotaxic Atlas of the Brain of the Baboon (Papio). London: Univ of Texas Press, Austin, 1968.

" Pasztor E, Symon L, Dorsch NWC, Branston NM. The hydrogen clearance method in assessment of blood flow in cortex, white matter and deep nuclei of baboons. Stroke 1973;4:556-67.

${ }^{12}$ Kuyama H, Fujimoto S, Nishimoto K, Ninomiya $K$, Akioka T, Matsumoto A, Nishimoto A. Measurement of regional cerebral blood volume by photoelectric method. Neurol Med Chir 1978;18:655-64.

${ }^{13}$ Branston NM, Ladds A, Symon L, Wang AD. Comparison of the effects of ischaemia on early components of the somatosensory evoked potential in brainstem, thalamus and cerebral cortex. In press.

${ }^{14}$ Harris RJ, Bayhan M, Branston NM, Watson A, Symon L. Modulation of the pathophysiology of primate focal cerebral ischaemia by indomethacin. Stroke 1982;13:17-24.

${ }^{15}$ Kamiya K, Kuyama H, Symon L. An experimental study of the acute stage of subarachnoid haemorrhage. In press.

${ }^{16}$ Symon L, Branston NM, Chickovani O. Ischaemic brain oedema following middle cerebral artery occlusion in baboons: Relationship between regional cerebral water content and blood flow at 1 to 2 hours. Stroke 1979;10:184-91.

${ }^{17}$ Kapp J, Mahaley MS, Odom GL. Cerebral arterial spasm. Part 2: Experimental evaluation of mechanical and humoral factors in pathogenesis. $J$ Neurosurg 1968;29:339-49.

${ }^{18}$ Osaka K. Prolonged vasospasm produced by the breakdown products of erythrocytes. $J$ Neurosurg 1977;47:403-11.

${ }^{19}$ Hayakawa T, Waltz AG. Experimental subarachnoid haemorrhage from a middle cerebral artery: Neurologic deficits, intracranial pressures, blood pressures and pulse rates. Stroke 1977;8:421-6.

${ }^{20}$ Asano T, Sano K. Pathogenetic role of no-reflow phenomenon in experimental subarachnoid haemorrhage in dogs. $J$ Neurosurg 1977;46:454-66.

21 Jakubowski J, Bell BA, Symon L, Zawirski MB, Francis DM. A primate model of subarachnoid haemorrhage: Change in regional cerebral blood flow, autoregulation, carbon dioxide reactivity and central conduction time. Stroke 1982;13:601-11.

${ }^{22}$ Nagai H, Suzuki Y, Sugiura M, Noda S, Mabe H. Experimental cerebral vasospasm. Part 1: Factors contributing to early spasm. $J$ Neurosurg 1974;41:285-92.

${ }^{23}$ Herz DA, Baez S, Shulman K. Pial microcirculation in subarachnoid haemorrhage. Stroke 1975;6:417-24.

${ }^{24}$ Hart MN. Morphometry of brain parenchymal vessels following subarachnoid haemorrhage. Stroke 1980;11:653-5.

${ }^{25}$ Grubb RL Jr., Raichle ME, Eichling JO, Gado MH. Effects of subarachnoid haemorrhage on cerebral blood volume, blood flow, and oxygen utilization in humans. J Neurosurg 1977;46:446-53.

${ }^{26}$ Klose HJ, Volger E, Brechtelsbauer H, Heinich L, Schmid-Schönbein H. Microrheology and light transmission of blood I. The photometric effects of red cell aggregation and red cell orientation. Pfügers Arch 1972;333:126-39.

${ }^{27}$ Charm SE, Kurland GS. Blood rheology. In: Bergel DH, ed. Cardiovascular Fluid Dynamics. London: Academic Press 1972;157-203.

${ }^{28}$ Tomita M, Gotoh F, Sato T, et al. Photoelectric method for estimating haemodynamic changes in regional cerebral tissue. Am J Physiol 1978;235:H56-H63.

${ }^{29}$ Symon L. An experimental study of traumatic cerebral vascular spasm. J Neurol Neurosurg Psychiatry 1967;30:497-505.

${ }^{30}$ Grubb RL Jr, Raichle ME, Eichling JO. The effects of changes in $\mathrm{PaCO}_{2}$ on cerebral blood volume, blood flow and vascular mean transit time. Stroke 1974;5:630-9.

${ }^{31}$ Voldby Bo, Enevoldsen EM. Intracranial pressure changes following aneurysm rupture. Part 2: Associated cerebrospinal fluid lactacidosis. J Neurosurg 1982;56: 197-204.

32 Harper AM, Deshmukh VD, Rowan JO, Jennett WB. The influence of sympathetic nervous activity on cerebral blood flow. Arch Neurol 1972;27:1-6.

${ }^{33}$ Saito I, Ueda Y, Sano K. Significance of vasospasm in the treatment of ruptured intracranial aneurysms. $J$ Neurosurg 1977;47:412-29.

${ }^{34}$ Branston NM, Symon L, Strong AJ. Reversibility of ischaemically induced changes in extracellular potassium in primate cortex. $J$ Neurol Sci 1978;37:37-49.

${ }^{35}$ Shigeno T, Fritschka E, Brock M, Schramm J, Shigeno S, Cervos-Navarro J. Cerebral edema following experimental subarachnoid haemorrhage. Stroke 1982;13:368-79.

${ }^{36}$ Trojanowski T. Blood-brain barrier changes after experimental subarachnoid haemorrhage. Acta Neurochir 1982;60:45-54.

${ }^{37}$ Peterson EW, Cardoso ER. The blood-brain barrier following experimental subarachnoid haemorrhage. Part 1: Responses to insult caused by arterial hypertension. J Neurosurg 1983;58:338-44.

${ }^{38}$ Fujimoto T, Walker JT Jr, Spatz M, Klatzo I. Pathophysiologic aspects of ischaemic oedema. In: Pappius HM, Feindel W, eds. Dynamics of Brain Edema. Heidelberg Springer Verlag: 1976;171-80. 